\title{
Epidemiology of Increasing Hemo-Parasite Burden in Ugandan Cattle
}

\author{
Keneth Iceland Kasozi1,2*, Enoch Matovu33, Dickson Stuart Tayebwa1, \\ Jemimah Natuhwera ${ }^{1,4}$, Israel Mugezi ${ }^{2}$, Michael Mahero ${ }^{5}$ \\ ${ }^{1}$ Central Diagnostic Laboratory, Department of Pharmacy, Clinics and Comparative Medicine, College of \\ Veterinary Medicine Animal Resources and Biosecurity, Makerere University, Kampala, Uganda \\ ${ }^{2}$ Kiboga District Regional Veterinary Laboratory, Department of Production and Marketing, Local Government, \\ Kiboga, Uganda \\ ${ }^{3}$ Department of Bio-Molecular Resources and Bio-Laboratory Sciences, College of Veterinary Medicine Animal \\ Resources and Biosecurity, Makerere University, Kampala, Uganda \\ ${ }^{4}$ Mbarara District Regional Veterinary Laboratory, Department of Production and Marketing, Local Government, \\ Mbarara, Uganda \\ ${ }^{5}$ Department of Population Medicine, College of Veterinary Medicine, University of Minnesota, St. Paul, MN, \\ USA \\ Email: *kicelandy@gmail.com
}

Received 28 August 2014; revised 18 September 2014; accepted 30 September 2014

Copyright (C) 2014 by authors and Scientific Research Publishing Inc.

This work is licensed under the Creative Commons Attribution International License (CC BY). http://creativecommons.org/licenses/by/4.0/

\section{(c) (i) Open Access}

\begin{abstract}
Hemo-parasites (HP) are one of the major constraints to the economic development of the livestock industry in Uganda. Generally, the occurrence and importance of HP is a reflection of complex interactions involving the causative organisms, tick vectors, the vertebrate hosts and the environment. We carried out a cross sectional study to identify and determine the prevalence of the major HPs in Central and Western Uganda, to form a baseline for appropriate interventions. A total of 295 bovine samples were analyzed from 15 districts of Uganda; $56.3 \%$ being from the Central and $43.7 \%$ from the Western region of the country for a period of six months, and a questionnaire was administered to the farmers. Thin peripheral blood smears stained with Giemsa were used during the laboratory identification of the parasites. The disease prevalence was established at $47.4 \%, 6.7 \%, 1.9 \%$ and 14.4\% for Theleria parva, Babesia spp., Trypanasoma brucei, Anaplasma spp. with a corresponding disease risk ratio (DRR) of $67.4 \%, 9.5 \%, 2.6 \%, 20.5 \%$ respectively in Uganda. The odds of having an infection from the Central region were 1.7 times greater $(P<0.05)$ than those from the Western region with a corresponding risk ratio of 1.2 (CI.1.1, 2.84, 95\%), which showed that there exist marked differences between the two regions. Mean PCV was at 29.8\%, and majority (59\%) of infected animals had low PCV which varied across the months.
\end{abstract}

${ }^{*}$ Corresponding author.

How to cite this paper: Kasozi, K.I., Matovu, E., Tayebwa, D.S., Natuhwera, J., Mugezi, I. and Mahero, M. (2014) Epidemiology of Increasing Hemo-Parasite Burden in Ugandan Cattle. Open Journal of Veterinary Medicine, 4, 220-231.

http://dx.doi.org/10.4236/ojvm.2014.410026 
These showed that generally, cattle in the West are more severely affected by HP than those from the Central region. The questionnaire revealed that $100 \%$ of the farmer treatments are based on clinical sign presentation, with occasional reliance on veterinarians. In conclusion, the burden of hemo-parasites is steadily increasing across the regions, and the current policies are not helping farmers who are hit the hardest by the development of antibiotic and acaricide resistance. These findings, along with previous studies, suggest that eradication HP is not feasible unless there are radical changes implemented, and that current practices are expensive and unsustainable. Further studies would be carried out to provide knowledge on the level of antibiotic resistance for the promotion of veterinary public health and trade.

\section{Keywords}

\section{Hemo-Protozoan Parasites, Farming Practices, Uganda, Food Security}

\section{Introduction}

Hemo-parasites (HP) are of great economic impact on livestock, affecting $80 \%$ of the world's cattle population [1] [2]. In East and Central Africa the major disease with the highest cases of mortality is East Coast fever (ECF) [1] [3] which is caused by Theleria parva, transmitted by Rhipicephalus appendiculatus [4]. Other minor tickborne diseases in cattle include benign theileriosis babesiosis, anaplasma, cowdriosis caused by Theileria mutans [5], Babesia bigemina, Anaplas mamarginale and Erlichia ruminantium [5] respectively. HP cause economic losses due to high morbidity and mortality [6] [7], and losses incurred have hindered further advancement of the livestock sector in most developing countries including Uganda [3]. This has further made the attainment of the millennial developmental goals (MDGs), in particular the eradication of extreme poverty and hunger among developing countries elusive [8]. In small livestock, Erlichiosis is a great burden thus limiting productivity despite efforts by the international community in partnership with regional Governments to provide highly productive breeds through improved livestock technologies [9] [10]. The disease is endemic in various parts of Uganda [11] [12], and there is limited epidemiological data on the disease in this country. Anaplasma marginale and Anaplasma centrale have been detected among livestock in East Africa [1] [5] [13] in both small and large animal populations. These are transmitted by Boophilus decoloratus ticks, and mechanical transmission during herd vaccinations has been reported [14] [15] and Babesia bigemina vectored by Boophilus decoloratus has got a wide geographical distribution in the tropics [16]. Generally, tick-transmitted diseases such as Babesiosis and Theileriosis are of economic importance globally [17]-[19]. HP are a major threat to food security especially among the livestock dependent communities within the Sub Saharan Africa [6] [20]. Recent studies in Uganda [21]-[23] and South Africa [24] have shown that certain wild ungulates such as the Cape Buffalo, have continued to act as reservoirs for some of the HP. This challenge is highly magnified at the wildlife-livestock [21] interface within most rural communities which has further modified the epidemiology of the disease.

The characteristic low-coverage of diagnostic laboratories coupled with poor extension services has hindered development of the livestock industry, since farmers have limited knowledge on the occurrence of the HP. A study [11] in Northern Uganda (Gulu) showed that Theileria and Anaplasma were highly prevalent and mortality attributable to TBDs was evident. In a corresponding study, HP burden was shown to be due to ECF (79\%), Anaplasmosis (11\%), and Babesiosis (4.4\%) [25]. In Eastern Uganda (Soroti), a study [26] indicated Sero prevalence up-to 100\% HP burden in Bos indicus to East Coast Fever, Babesiosis and Anaplasmosis. In the Bos indicus (Nkedi Zebu), the prevalence of trypanosome infection was lower $(7.9 \% \mathrm{v} .10 .8 \%$; P > 0.05) with the overall mean PCV higher $(29.4 \%$ v. 28.7\%; P < 0.05) than in the Bos indicus (Ankole) [26]. In the Kenya highlands, recent studies [4] [27] [28] demonstrated that prevalence of T. parva infections and the reported ECF mortality and case-fatality can vary significantly by zones and grazing system [29]. In Kenya, intensive/semiintensive smallholder systems [30] were characterized by different management practices at the farm, agroecological level as well as grazing systems [4]. Consequently, they show varying ECF prevalence, incidence and ECF-specific morbidity and mortality rates and Kenya has recently approved ECF vaccination [17] in all production systems, thus farm management can improve on the outcomes of HP burden [31]. 
It's generally agreed that control of tick-borne diseases in Sub-Saharan Africa has failed because of lack of epizootiological information and control strategies [3] [32]. These would probably be due to the various social farming challenges at the community interface, controlled by a variety of factors ranging from Government policies, farming technologies, climate change, soil and vegetation to human activities including livestock production systems as well as measures taken to control ticks and treatment interventions done by the farmers. There is still a great lack of knowledge regarding the epidemiology of the increasing HP burden in the region despite the efforts from the regional Governments in the livestock sector to promote the MDGs [8]. In this study we carried out a survey to identify and determine the prevalence of the major HP in Central and Western Uganda. A questionnaire was administered and an on farm drug survey was conducted to determine any relationship between HP distribution and the seasons, farming practices in order to form a baseline for institution of relevant corrective measures within the study areas.

\section{Materials and Methods}

This was a cross sectional study carried out (along the cattle corridor of West and Central) from September 2013 to February 2014. A total of 143 farmers from 15 districts in Central (Kampala, Kiboga, Kyankwanzi, Luwero, Lyantonde, Masindi, Mukono, Wakiso) and Western (Fort-portal, Ibanda, Isingiiro, Kamwenge, Kibaale, Kiruhura, and Mbarara districts) were covered. Farms for inclusion were selected through veterinary records from the local Government, accessibility and history of tick borne infections following recent episodes of treatment and acaricide application and an open ended questionnaire along with a drug survey was structured and administered by an interviewer. Adult ( $\geq 1.5$ years) and yearlings ( $<1.5$ year) were considered, while the major breeds considered were Bos indicus (Ankole, Zebu), Bos taurus (Friesian, Boran, Guernsey, and Jersey). We included all cattle with and without clinical signs of HP infection (ill thrift, anemia, temperature of $>40.5^{\circ} \mathrm{C}$ ) on the farms, those that had been treated within the last 14 days or had undergone acaricide application within the last 7 days, as well as those animals that had not received any chemotherapeutical intervention by the farmer. Thin peripheral blood smears stained with Giemsa were used during the laboratory identification of the parasites. Briefly, blood was collected from the coccygeal vein following effective restraint of the cattle under study using a field improvised crush, from which thin blood smears were prepared in the laboratory. The smears were fixed with methanol, stained with Giemsa and examined under $\times 1000$ magnification with oil immersion. Heparinized blood was placed in micro-hematocrit tubes, and centrifuged at 10,000 rpm for 4 minutes; afterward the PCV was determined using the hematocrit reader. The identified parasites were hence recorded against the respective animal, along with their individual corresponding PCV readings. Data entry was done using Excel version 2010, and analysis by Excel and Epi-Info software. Logistic regression was used to examine the relationship between farmer treatment interventions and the other risk factors thought to be responsible for the observations made. Ethical Approval was got through The College of Veterinary Medicine and Animal resources and Biosecurity.

\section{Results}

A total of 295 bovine samples were analyzed; 56.3\% from the Central and 43.7\% from the Western region of the country over a period of six months (September 2013 to February 2014) at 95\% confidence interval as shown in Table 1.

The mean PCV reading was 29.8\%, while the regional readings were 30.5\%, 28.8\% (SD: 7.9, 8.2) for Central and Western regions respectively as shown in Table 2. The majority (59\%) of the animals that were positive with hemo-parasites (HP) had a PCV below the mean, while $41 \%$ among the infected had a PCV above the mean (29.8). It was also discovered that $57.4 \%$ among the animals negative with HP, had a PCV > 29.8, while 42.6\% had a PCV $\geq 29.8$. Of the cattle samples obtained (295), those from the Central region had a higher burden of HP than those from the Western at $61.9 \%$ and $38.1 \%$ respectively. Infection with HP was highest (70.7\%) among Bos indicus while in the Bos taurus it was established at $57.9 \%$ from the study area. The HP burden increased steadily across the months as shown in Table 3. Generally disease burden was higher in farmers that had not attempted any treatment than those that had tried to intervene. Majority (60\%) of the farmers used antibiotics, while 30\% used anti-protozoan agents, while the rest offered no treatment intervention. HP parasites were detected in cattle samples from farmers that had attempted treatment with anti-protozoan agents (70.7\%), and those that had used antibiotics (50.7\%), while in farmers that had not attempted any intervention; it was established at $63.9 \%$ as shown in Table 3. 
Table 1. Showing Regional bovine sample distribution in the study area.

\begin{tabular}{rccc}
\hline \multirow{2}{*}{ Region } & Samples & \multicolumn{2}{c}{ 95\% Confidence Interval } \\
\cline { 2 - 4 } & Freq. (\%) & Lower & Upper \\
\hline Central & $166(56.3)$ & 50.4 & 62.0 \\
Western & $129(43.7)$ & 38.0 & 49.6 \\
\hline
\end{tabular}

Table 2. Showing PCV distribution across the Central and Western regions.

\begin{tabular}{cccc}
\hline & & Results & Western \\
\cline { 2 - 4 } Parameters & Total & Central & 10.0 \\
Minimum & 10.0 & 10.0 & 60.0 \\
Maximum & 68.0 & 68.0 & 28.8 \\
Mean & 29.8 & 30.5 & 8.2 \\
Std. Dev. & 8.1 & 7.9 & 129 \\
Observations & 295 & 166 & 169 \\
\hline
\end{tabular}

Table 3. Showing descriptive statistics from bovine samples in the study area.

\begin{tabular}{|c|c|c|c|}
\hline \multirow{2}{*}{ Parameter } & \multirow{2}{*}{ Variable } & \multicolumn{2}{|c|}{ Frequency Distribution (\%) } \\
\hline & & Positive & Negative \\
\hline \multirow{2}{*}{ PCV } & $<29.8$ & $36(59)$ & $139(57.4)$ \\
\hline & $\geq 29.8$ & $25(41)$ & $103(42.6)$ \\
\hline \multirow{2}{*}{ Regional Burden } & Central & 109 (61.9) & 57 (47.9) \\
\hline & Western & $67(38.1)$ & $62(52.1)$ \\
\hline \multirow{2}{*}{ Breed } & Bos indicus & $29(70.7)$ & $12(29.3)$ \\
\hline & Bos taurus & 147 (57.9) & $107(42.1)$ \\
\hline \multirow{2}{*}{ Age } & Adult & $172(60.4)$ & $113(39.4)$ \\
\hline & Yearling & $4(40)$ & $6(60)$ \\
\hline \multirow{6}{*}{ Month } & September & $16(48.5)$ & $17(51.5)$ \\
\hline & October & 27 (81.8) & $6(18.2)$ \\
\hline & November & 35 (59.3) & $24(40.7)$ \\
\hline & December & 30 (69.8) & $13(30.2)$ \\
\hline & January & 55 (58.5) & 39 (41.5) \\
\hline & February & 13 (39.4) & $20(60.6)$ \\
\hline \multirow{2}{*}{ Treatment Groups } & No treatment intervention & 39 (63.9) & $22(36.1)$ \\
\hline & Treatment intervention & $137(58.5)$ & $97(41.5)$ \\
\hline \multirow{3}{*}{ Treatment Interventions } & No treatment offered & 39 (63.9) & $22(36.1)$ \\
\hline & Anti-protozoan & 65 (70.7) & 27 (29.3) \\
\hline & Antibiotic & $72(50.7)$ & $70(49.3)$ \\
\hline
\end{tabular}

In the present study, the disease prevalence was established at $47.4 \%, 6.7 \%, 1.9 \%$ and $14.4 \%$ for $T$. parva, Babesia spp., T. brucei, Anaplasma spp. with a corresponding disease risk ratio (DRR) of 67.4\%, 9.5\%, 2.6\%, 20.5\% respectively for Central and Western regions of Uganda as shown in Table 4. The odds of having an infection from the Central region were 1.7 times greater than those from the Western region with a corresponding risk ratio of 1.2 (CI.1.10, 2.84, 95\%), which showed that there exists marked differences between the two zones as shown in the Table 5.

There was a significant difference in the odds of exposure and risk of infection between the two regions in the study area (Chi-square p value $<0.01$ ). Prevalence of Theileria and Anaplasma infection in Western region was 
Table 4. Shows the hemo-protozoan isolates and their burden in from the selected districts of Uganda.

\begin{tabular}{ccccc}
\hline Variable & T. parva & Babesia spp. & T. brucei & Anaplasma spp. \\
\hline Prevalence & 47.4 & 6.7 & 1.9 & 14.4 \\
DRR & 67.4 & 9.5 & 2.6 & 20.5 \\
\hline
\end{tabular}

Key: DRR $=$ disease risk ratio.

Table 5. Showing odds and risk ratios for hemo-protozoan infection in bovine samples from the study area.

\begin{tabular}{|c|c|c|c|c|c|}
\hline \multirow{2}{*}{\multicolumn{2}{|c|}{ Parameters: }} & \multirow{3}{*}{$\begin{array}{c}\text { Point Estimate } \\
1.7696\end{array}$} & \multicolumn{3}{|c|}{ 95\% Confidence Interval } \\
\hline & & & \multirow{2}{*}{$\begin{array}{l}\text { Lower } \\
1.1048\end{array}$} & \multicolumn{2}{|l|}{ Upper } \\
\hline \multirow[t]{3}{*}{ Odds Ratio } & (cross product) & & & 2.8344 & (T) \\
\hline & & & 1.0749 & 2.9128 & (F) \\
\hline & Risk-based & & & & \\
\hline Risk Ratio & (DRR) & 1.2643 & 1.036 & 1.5428 & $(\mathrm{~T})$ \\
\hline Risk Difference & (RD\%) & 13.7247 & 2.4767 & 24.9726 & $(\mathrm{~T})$ \\
\hline
\end{tabular}

Key: $\mathrm{T}$ = Taylor Series; F = Fisher Exact.

$56.2 \%$ and $24.8 \%$, while that in the Central region was at $40.0 \%, 6.0 \%$ respectively. The Trypanosome prevalence infection was $80 \%$ in Western, while it was $20 \%$ in the Central region with a corresponding Babesiosis prevalence of $9.9 \%$ and $4.0 \%$ respectively as shown in Table 6 .

The drug survey carried out showed that all the farmers in the respective districts had full access to the antibiotics and anti-protozoan agents as well as acaricides from the regional veterinary drug shops. The odds of having a HP positive cattle following treatment intervention were established at 1.2 times less likely to those from animals that didn't receive treatment by the farmer as shown in Table 7. Statistical analysis showed there is no significant association between animals that had been treated and those that had not been treated $(\mathrm{P}=0.23)$ by the farmers in this study.

\section{Factors that Would Probably Be Responsible for Differences in the HP Burden in the Two Regions}

HP burden was significantly associated with season/month of the year $(\mathrm{P}<0.01)$. In a stepwise logistic regression analysis using variables identified from the bivariate analysis only one variable-Month (Dec/Feb-Odds ratio 6.18; $\mathrm{P}=0.02$ ) was independently associated to HP burden. Further analysis of farmer treatment practices on the individual HP prevalence revealed a higher infection rate in treated compared to non-treated bovines as shown in Table 8. There was no significant difference in the presence of HP and treatment, thus treatment type was not significantly associated with the presence or absence of hemo-protozoan parasites as shown in Table 9 .

Majority (60.4\%) of the infected animals were adults, while only $40 \%$ of the yearlings were infected as shown in Table 3 and further analysis showed there was no significant association between age and infection $(\mathrm{P}>0.05)$ with HP.

The questionnaire revealed that $100 \%$ of the treatments done by farmers were based on their knowledge of the clinical signs without necessarily consulting veterinarians. Among those that relied on veterinarians, $84 \%$ were from the Central region while 16\% from the Western region of Uganda. $65 \%$ of the farmers in the Central region attempted treatment without consulting veterinarians. Farmer treatment therapeutical failures of $50 \%$ from both regions were reported. Farmers continue to face a couple of limitations in the industry such as expensive drugs and limited laboratory coverage (100\% Central) and limited Government support (83.3\%, 16.7\%) in the Central and Western regions respectively. The results are further summarized in Table 10.

\section{Discussion}

In this study, more samples (Table 1) were collected from the Central region probably due to convenience, and demand for laboratory veterinary diagnostic services within these communities. Prevalence of Theileria and Anaplasma infection was highest in Western region from this study, which showed a 50\% increment from previous studies in both Northern and Eastern regions of Uganda [1] [11]. It was also shown that infection with 
Table 6. Showing the regional burden in cattle from the individual hemo-parasites.

\begin{tabular}{ccccccc}
\hline Region & Average Counts & T. parva & Babesia spp. & T. brucei & Anaplasma spp. & Negative \\
\hline Central (\%) & $150(28.9)$ & $60(40)$ & $6(4.0)$ & $1(0.7)$ & $9(6.0)$ & $74(49.3)$ \\
Western (\%) & $121(28.9)$ & $68(56.2)$ & $12(9.9)$ & $4(3.3)$ & $30(24.8)$ & $38(31.4)$ \\
\hline
\end{tabular}

Table 7. Showing data output on effect of farmer treatments on HP and those that hadn't intervened.

\begin{tabular}{|c|c|c|c|c|c|}
\hline \multirow{2}{*}{\multicolumn{2}{|c|}{ Parameters }} & \multirow[t]{2}{*}{ Point Estimate } & \multicolumn{3}{|c|}{ 95\% Confidence Interval } \\
\hline & & & \multirow[t]{2}{*}{ Lower } & \multirow[t]{2}{*}{ Upper } & \\
\hline Odds-Based & & & & & \\
\hline Odds Ratio & (cross product) & 1.2551 & 0.7001 & 2.2502 & $(\mathrm{~T})$ \\
\hline \multirow[t]{2}{*}{ Odds Ratio } & (MLE) & 1.2542 & $\underline{0.7014}$ & $\underline{2.2771}$ & $(\mathrm{M})$ \\
\hline & & & 0.6764 & 2.3706 & $(\mathrm{~F})$ \\
\hline \multicolumn{6}{|l|}{ Risk-Based } \\
\hline Risk Ratio & (DRR) & 1.092 & 0.8789 & 1.3569 & $(\mathrm{~T})$ \\
\hline Risk Difference & (RD\%) & 5.3874 & -8.2162 & 18.9919 & $(\mathrm{~T})$ \\
\hline
\end{tabular}

Key: $\mathrm{T}$ = Taylor Series; $\mathrm{C}$ = Cornifield; $\mathrm{M}=$ Mid P; F = Fisher Exact.

Table 8. Showing HP burden in treated cattle populations by farmers in the study area.

\begin{tabular}{ccccccccc}
\hline \multirow{2}{*}{ Variable } & \multicolumn{9}{c}{ Frequency (\%) } \\
\cline { 2 - 9 } & \multicolumn{2}{c}{ T. parva } & \multicolumn{2}{c}{ Anaplasma spp. } & \multicolumn{2}{c}{ Babesia spp. } & \multicolumn{2}{c}{ T. brucei } \\
\cline { 2 - 9 } & Post. & Neg. & Post. & Neg. & Post. & Neg. & Post. & Neg. \\
\hline No Treatment & $27(18.8)$ & $34(22.7)$ & $11(28.2)$ & $50(19.5)$ & $2(10)$ & $59(21.5)$ & $1(16.7)$ & $60(20.8)$ \\
Antiprotozoan & $56(38.9)$ & $36(24)$ & $18(46.2)$ & $74(28.9)$ & $9(45)$ & $83(30.2)$ & $3(50)$ & $89(30.8)$ \\
Antibiotic & $61(42.4)$ & $80(53.3)$ & $10(25.6)$ & $132(51.6)$ & $9(45)$ & $133(48.4)$ & $2(33.3)$ & $140(48.4)$ \\
\hline
\end{tabular}

Key: Post $=$ Positive; Neg = Negative.

Table 9. Showing relationship between presence of HP and farmer treatments.

\begin{tabular}{ccccc}
\hline Variable & Chi-square & Df & Probability & Comment \\
\hline T. parva & 7.5921 & 2 & 0.0225 & $\mathrm{P}<0.05$ \\
Anaplasma spp. & 9.1840 & 2 & 0.0101 & $\mathrm{P}<0.05$ \\
Babesia spp. & 2.5395 & 2 & 0.2809 & $\mathrm{P}>0.05$ \\
T. brucei & 1.0215 & 2 & 0.6000 & $\mathrm{P}>0.05$ \\
\hline
\end{tabular}

hemo-parasites was highest (70.7\%) among Bos indicus while in the Bos taurus it was established at 57.9\% (Table 3), which is contrary to recent findings [1] [26] that indicated stability in Bos indicus. This would probably due to the farmer management practices in the rural communities which have led to the endemic instability of the parasites in the livestock populations. Generally, in both regions, farmers did offer medications without consultations from veterinarians due to the liberalization of the livestock industry [33], and they often wait until the condition has deteriorated thus accounting for the increased animal loses due to HP and the steady increase of the their prevalence within Uganda. Overall disease burden was lower in farmers that had not attempted any treatment than those that had tried to intervene.

Amongst farmers that attempted treatment, majority of them used antibiotics and anti-protozoa agents, while the rest offered no treatment intervention. HP were detected in cattle samples from farmers that had attempted treatment with anti-protozoan agents (70.7\%), which was higher than in those that that claimed to have used antibiotics (50.7\%) as shown in Table 3. The farm surveys also showed that the control of HP and vectors basically relied on the use of anti-protozoan agents as well as (Table 3) antibiotics which concurs with previous 
Table 10. Showing Questionnaire responses from the study area.

\begin{tabular}{|c|c|c|c|c|}
\hline Qtn. & Variable & Response & Central (\%) & Western $(\%)$ \\
\hline 1 & Disease identification & Clinical signs & $92(64.3)$ & $51(35.7)$ \\
\hline \multirow{2}{*}{2} & \multirow{2}{*}{ Treatment options } & Treatment with pharmaceutical agents & $78(65)$ & $42(35)$ \\
\hline & & Didn't offer any treatment & $22(45.8)$ & $26(54.2)$ \\
\hline \multirow{2}{*}{3} & \multirow{2}{*}{ Drug availability } & Drug shops & $82(62.1)$ & $50(37.9)$ \\
\hline & & Hawkers & $10(90.9)$ & $1(9.1)$ \\
\hline \multirow{2}{*}{4} & \multirow{2}{*}{ Human resource } & Consulted veterinarian & $21(84)$ & $4(16)$ \\
\hline & & Seasonally relied on Veterinarian & $71(60.2)$ & 47 (39.8) \\
\hline \multirow{6}{*}{5} & \multirow{6}{*}{ Challenges faced } & No improvement after treatment & $20(50)$ & $20(50)$ \\
\hline & & Unreliable veterinary services & $22(62.9)$ & $13(37.1)$ \\
\hline & & Acaricide resistance & $74(64.9)$ & $40(35.1)$ \\
\hline & & Drugs expensive & $11(100)$ & $0(0)$ \\
\hline & & Limited Vet laboratories & $7(100)$ & $0(0)$ \\
\hline & & Limited Government support & $5(83.3)$ & $1(16.7)$ \\
\hline \multirow{6}{*}{6} & \multirow{6}{*}{ Complications to HP control } & NDA + Few Veterinarians & $19(67.9)$ & $9(32.1)$ \\
\hline & & ECF vaccination & $1(100)$ & $0(0)$ \\
\hline & & Death of animals & $18(60)$ & $12(40)$ \\
\hline & & Fake vet drugs on the market & $5(55.6)$ & $4(44.4)$ \\
\hline & & Government policy and politics & $11(68.8)$ & $5(31.3)$ \\
\hline & & Climate change (droughts) & $9(81.8)$ & $2(18.2)$ \\
\hline \multirow{2}{*}{7} & \multirow{2}{*}{$\begin{array}{l}\text { Production system } \\
\text { (Observations) }\end{array}$} & Semi-intensive & $84(93)$ & $6(7)$ \\
\hline & & Extensive & $60(40)$ & $90(60)$ \\
\hline
\end{tabular}

Key: NDA = National Drug Authority.

findings [12] [34] while some farmers offered no chemotherapeutical treatment. It was also observed that the limited human resource at the regional local Governments was not being fully utilized, thus making disease diagnosis and control further more complicated under the prevailing Government policies, thus contributing to the slow development of the livestock industry through increased animal mortalities and poor farming practices that have culminated into the severe climatic changes in these farming communities as shown in Table 10. The Government's policy on liberalization [33], of the drug industry has been a great failure, because, the end point of the policy, was not to improve accessibility, but improve animal health and productivity and from our observations this is still elusive.

The findings Table 2 and Table 3 showed that generally, cattle in the Western region are more severely affected by HP than those from the Central region, and PCV alone wouldn't be used as measure of HP presence. Central region had a higher burden of HP than those from the Western (Table 3). This would probably be because the Central region lies more within the mixed rain-fed crop-livestock category in Uganda, which has a better climate favorable for farming [6] which would further indicate that the burden of HP. The absence of screening centers for inter-district animal movements against animal diseases in the regions has further escalated the situation [35]. Generally the occurrence and importance of HP is a reflection of complex interactions involving the causative organisms, tick vectors, the vertebrate hosts and the environment [3]. These interactions are driven and modified by a wide variety of factors ranging from the environment, host, and the vectors as well as community farming activities. Trypanosome prevalence infection was four times greater in Western region than in the Central region (Table 6), which concurs with the findings of Rubaire [12] in Eastern Uganda which showed that prevalence of HP in cattle vary with agro-ecological zones and management [4] [27] in the Kenyan highlands. The Western region is also bordered (Smith et al., 2010) by a couple of National Game Parks (NGPs) which continue to act as reservoirs for maintenance [26] and carrier hosts [21] [22] in the regional farms as wildlife and cattle often intermingle during grazing. Human activities especially in the land use pattern of the 
farming communities around the NGPs, as cattle grazers encroach on the game park pastures have resulted in an increased incidence of the HP [21]. This risk is higher in the Western region, and as communities continue to move long distances in search of water and pastures in the long dry seasons which have been worsened by the climatic changes in the region, probably accounting for the higher observed DRR over that in the Central region.

The current livestock policy [33] has yielded undesirable effects that have continued to undermine the development of the livestock industry (Table 10). This has led to the proliferation of the HP burden due to the maintenance of chronic carriers [11] within the communities. This would be due to the fact that most farmers find the services costly and would prefer not allowing the veterinarian to visit them [33] coupled with limited supervision of the veterinary drug industry by National Drug Authority (NDA), which has led to the development of antibiotic and acaricide resistance in the farming communities which has been induced by the farmers. The current dilemma facing the food animal drug use is probably due to the lack of appropriate guidance on proper drug usage, medication to use for a particular parasite, probably due to the poor Government policy in the livestock industry [34], as well as inadequate supervision of the drug industry (NDA) and ineffective extension service delivery as a result of shortage of professional human resource in these communities. This is further worsened by the poor attitude amongst farmers as they seldom rely on district veterinary laboratories [36] for a diagnosis, to gain a better knowledge on their individual herd challenges before treatment is instituted [11]. This would probably also be due to the few veterinary laboratories in the countryside or the shortage of human resource to operate them at the local Government level, thus leading to the development of this trend in farming practices which have continued to favor the proliferation of HPs within Uganda despite all the various policies in place.

The HP burden increased steadily from September and decreased through January. This would be due to the seasonal variations as the tick population increases exponentially during the rainy season (September to November) and logistic regression showed no significant association for the other months except for the Months of December/February (dry season). This would probably have been due to the vector epidemiological dynamics as the tick (vector) challenge is highest in the rainy seasons, thus the observed increases in the HP challenge, and farmers are often vigilant to intervene and administer treatments. In the dry season, most of the severely challenged animals died due to increased stress levels from water shortage, limited pastures and severe mineral deficiencies in addition to the suppressed immune system as a result of the chronic infections due to HP. Cattle were observed to come down with infection as the dry season intensified (December to February) and more livestock losses were registered from several farms. Statistical analysis showed there was no significant association between cattle that had been treated and those that had not been treated by the farmers in this study. This would probably be due to the fact that farmer treatments are often ineffective due to their failure to seek professional assistance and adherence to dosage regiments, as well as poor diagnosis of HP conditions with other differential infections [11] within the community as they seldom rely on laboratory diagnosis. Cheap antibiotics that don't clear off infection are preferred to anti-HP agents which are relatively expensive. The current Government policy regarding veterinary drug usage has contributed to the development of drug resistance in the cattle in several farms, which has led to the proliferation of HP in the rural communities especially. Farmer treatment efficacy on the individual HP was further analyzed and it was discovered infection rate was higher in treated than nontreated groups as shown in Table 8. This observation was due to the fact that resistance had developed in the Ugandan cattle to the antibiotics that had overly been abused over the years [37]. There was no association between age and the infection of the cattle with HP despite of the fact that majority of infected animals were adults, which would be due to the fact that adult cattle move great distances in search of pastures and the yearlings are kept nearby the farm thus less exposed to the risk of HP.

The increasing HP burden is attributed to the farming practices, increased antibiotic and acaricide resistance [38] as well as failure by farmers to adhere to the therapeutical regiment for effective treatment, and epidemiological pattern of the dominant ticks in the region [12] as well as the current government policy. The findings, together with those of previous studies, suggest that eradication of hemo-parasites is not feasible unless there are radical changes implemented, and that current practices are expensive and given the indigenous nature of the breeds, also epidemiologically unsound [34] [39]. In addition, veterinary costs for animal health service delivery are apparently high especially following the liberalization [33] of the livestock industry. An ethno-veterinary approach combined with social service delivery to improve on behavioral change on farming practices, and drug usage, improved extension service delivery as well as efficient livestock industry management may be required for the sustainability of the livestock industry to control the increasing HP burden in the farming communities of Uganda and the neighboring East and Central African countries. 


\section{Conclusion and Recommendations}

The burden of hemo-parasites is steadily increasing across the regions, and the current policies are not helping farmers who are hit the hardest by the development of antibiotic and acaricide resistance. There is an urgent need to design strategic control methods that are integrated in the production systems which would rely on renewable resources within our ecosystem especially for the respective regions along the cattle corridor of Uganda, through improved policy, research and extension service delivery in the livestock sector for the growth and development of the industry. Further research would be carried out to evaluate the Veterinary Public Health concerns that are raised by these threats especially for the promotion of both human and veterinary medical fields within the diaspora.

\section{Acknowledgements}

We would like to thank all the Farmers that participated in this work, and the district officials at the respective Local Governments. The study was carried out as part of the Japanese Technical Assistance to Improve the National Diagnostic Capacity for Animal Disease Control in Uganda. The study was funded in part by the Japan International Cooperation Agency.

\section{References}

[1] Muhanguzi, D., Picozzi, K., Hatendorf, J., Thrusfield, M., Welburn, S.C., Kabasa, J.D. and Waiswa, C. (2014) Prevalence and Spatial Distribution of Theileria parva in Cattle under Crop-Livestock Farming systems in Tororo District, Eastern Uganda. Parasit Vectors, 7, 91. http://dx.doi.org/10.1186/1756-3305-7-91

[2] Minjauw, B. and McLeod, A. (2003) Tick-Borne Diseases and Poverty. The Impact of Ticks and Tick-Borne Diseases on the Livelihood of Small-Scale and Marginal Livestock Owners in India and Eastern and Southern Africa. UK: Research Report, DFID Animal Health Programme, Centre for Tropical Veterinary Medicine, University of Edinburgh. http://r4d.dfid.gov.uk/PDF/Outputs/RLAHTickBorn_Book.pdf

[3] Norval, R.A.I., Perry, B.D. and Young, A.S. (1992) The Epidemiology of Theileriosis in Africa. Academic Press Ltd., London, 481.

[4] Gitau, G.K., Perry, B.D., Katende, J.M., McDermott, J.J., Morzaria, S.P. and Young, A.S. (1997) The Prevalence of Serum Antibodies to Tick-Borne Infections in Cattle in Smallholder Dairy Farms in Murang'a District, Kenya; a Cross-Sectional Study. Preventive Veterinary Medicine, 30, 95-107. http://dx.doi.org/10.1016/S0167-5877(96)01100-2

[5] Wesonga, F.D., Kitala, P.M., Gathuma, J.M., Njenga, M.J. and Ngumi, P.N. (2010) An Assessment of Tick-Borne Diseases Constraints to Livestock Production in a Smallholder Livestock Production System in Machakos District, Kenya. http://www.lrrd.org/lrrd22/6/weso22111.htm

[6] Mapping a Better Future (2014) An Overview of Livestock and Poverty. Spatial Analysis and Pro-Poor Livestock Strategies in Uganda, 12-22. http://www.wri.org/sites/default/files/pdf/mapping_a_better_future_livestock_overview.pdf

[7] Perry, B.D. and Young, A.S. (1995) The Past and Future Roles of Epidemiology and Economics in the Control of Tick-Borne Diseases of Livestock in Africa: The Case of Theileriosis. Preventive Veterinary Medicine, 25, 107-120. http://dx.doi.org/10.1016/0167-5877(95)00546-3

[8] MDG (2014) Millennial Developmental Goals Report. http://www.un.org/millenniumgoals/2014\%20MDG\%20report/MDG\%202014\%20English\%20web.pdf

[9] Anthony, M., Kayiizi, V., Owiny, D. and Mburu, J. (2014). Breeding Services and the Factors Influencing Their Use on Smallholder Dairy Farms in Central Uganda. Veterinary Medicine International, 2014, Article ID: 169380. http://downloads.hindawi.com/journals/vmi/2014/169380.pdf

[10] Uilenberg, G. and Camus, E. (1993) Heartwater (Cowdriosis). In: Woldehiwet, Z. and Ristic, M.W., Eds., Rickettsial and Chlamydial Diseases of Domestic Animals, Pergamon Press, Oxford, 293-232.

[11] Angwech, H., Kaddu, J.B. and Nyeko, J.H.P. (2011) Tick-Borne Parasites of Domestic Ruminants in Gulu District, Uganda: Prevalence Varied with the Intensity of Management. Veterinary Research, 4, 28-33. www.medwelljournals.com/fulltext/?doi=vr.2011.28.33

[12] Rubaire-Akiiki, C., Okello-Onen, J., Nasinyama, G.W., Vaarst, M., Kabagambe, E.K., et al. (2004) The Prevalence of Serum Antibodies to Tick-Borne Infections in Mbale District, Uganda: The Effect of Agro-Ecological Zone, Grazing Management and Age of Cattle. Journal of Insect Science, 4, 8. http://www.insectscience.org/4.8/Rubaire_et_al_JIS_4_8_2004.pdf

[13] Ristic, M. (1968) Volume 2: Anaplasmosis. In: Weinman, D. and Ristic, M., Eds., Infectious Blood Diseases of Man 
and Animals, Academic Press, New York, 473-542.

[14] Ueti, M.W., Palmer, G.H., Scoles, G.A., Kappmeyer, L.S. and Knowles, D.P. (2008) Persistently Infected Horses Are Reservoirs for Intrastadial Tick-Borne Transmission of the Apicomplexan Parasite Babesia equi. Infection and Immunity, 76, 3525-3529. http://dx.doi.org/10.1128/IAI.00251-08

[15] Maloo, S.H. (1993) Epidemiological Study of Vector Borne Diseases with Consequent Development of Preventive Veterinary Programmes for Small Holder Dairy Farms in Coastal Kenya. Ph.D. Thesis, University of Glasgow, Glasgow.

[16] de Vos, A.J., Bock, R.E. and Molloy, J.B. (2006) Tick-Borne Diseases of Cattle. Tick Fever Centre Biosecurity, Molecular Bioscience Technologies, Department of Primary Industries and Fisheries, Animal Research Institute, Australia. http://www.scahls.org.au/Procedures/Documents/ANZSDP/tick_borne_diseases.pdf

[17] Lynen, G., Yrjö-Koskinen, A.E., Bakuname, C., Di Giulio, G., Mlinga, N., Khama, I., Hanks, J., Taylor, N.M., James, A.D., McKeever, D., Peters, A.R. and Rushton, J. (2012) East Coast Fever Immunisation Field Trial in Crossbred Dairy Cattle in Hanang and Handeni Districts in Northern Tanzania. Tropical Animal Health and Production, 44, 567572. http://dx.doi.org/10.1007/s11250-011-9936-8

[18] Altay, K., Dumanli, N. and Aktas, M. (2007) Molecular Identification, Genetic Diversity and Distribution of Theileria and Babesia Species Infecting Small Ruminants. Veterinary Parasitology, 147, 161-165. http://dx.doi.org/10.1016/j.vetpar.2007.04.001

[19] Otim, C.P. (2000) Advances in Disease Control: Ticks and Tick-Borne Diseases. The Uganda Journal of Agricultural Sciences, 5, 79-85.

[20] Bell-Sakyil, L., Koneye, E.B.M., Dogbeyo, O. and Walker, A.R. (2004) Incidence and Prevalence of Tick-Borne Haemoparasites in Domestic Ruminants in Ghana. Veterinary Parasitology, 124, 25-42. http://dx.doi.org/10.1016/j.vetpar.2004.05.027

[21] Kabuusu, R.M., Alexander, R., Kabuusu, A.M., Muwanga, S.N., Atimnedi, P. and Macpherson, C. (2013) Effect of a Wildlife-Livestock Interface on the Prevalence of Intra-Erythrocytic Hemoparasites in Cattle. Open Journal of Veterinary Medicine, 3, 315-318. http://dx.doi.org/10.4236/ojvm.2013.38051

[22] Ocaido, M., Muwazi, R.T. and Opuda-Asibo, J. (2009) Disease Incidence in Ranch and Pastoral Livestock Herds around Lake Mburo National Park, in South Western Uganda. Tropical Animal Health and Production, 41, 1299-1308. http://dx.doi.org/10.1007/s11250-009-9315-X

[23] Paling, R.W., Mpagala, C., Luttinhuizen, B. and Sibomana, G. (1991) Exposure of Ankole Cattle and Crossbred Cattle to Theileriosis in Rwanda. Tropical Animal Health and Production, 23, 203-214. http://dx.doi.org/10.1007/BF02357101

[24] Smith, E.R. and Parker, D.M. (2010) Tick Communities at the Expanding Wildlife/Cattle Interface in the Eastern Cape Province, South Africa: Implications for Corridor Disease. Journal of the South African Veterinary Association, 81, 237-240. http://www.jsava.co.za/index.php/jsava/article/download/154/140

[25] Magona, J.W., Walubengo, J. and Odimim, J.J. (1998) Differences in Susceptibility to Trypanosome Infection between Nkedi Zebu and Ankole Cattle, under Field Conditions in Uganda. Annals of Tropical Medicine and Parasitology, 98, 785-792.

[26] Kabi, F., Magona, J.W., Nasinyama, G.W. and Walubengo, J. (2008) Seroprevalence of Tick Borne Infections among the Nkedi Zebu and Ankole Cattle in Soroti District, Uganda. Journal of Protozoology Research, 18, 61-70. http://dx.doi.org/10.1179/000349804225021532

[27] Gitau, G.K., Perry, B.D. and McDermott, J.J. (2000) The Incidence, Calf Morbidity and Mortality Due to Theileriaparva Infections in Smallholder Dairy Farms in Murang’a District, Kenya. Preventive Veterinary Medicine, 39, 65-79. http://dx.doi.org/10.1016/S0167-5877(98)00137-8

[28] Deem, S.L., Perry, B.D., Katende, J.M., McDermott, J.J. and Mahan, S.M., et al. (1993) Variations in Prevalence Rates of Tick-Borne Diseases in Zebu Cattle by Agroecological Zone: Implications for East Coast Fever Immunisation. Preventive Veterinary Medicine, 16, 171-187. http://dx.doi.org/10.1016/0167-5877(93)90064-Z

[29] Sombroek, W.G., Braun, H.M. and van der Pouw, B.J. (1982) Exploratory Soil Map and Agroclimatic Zones Map of Kenya. Exploratory Soil Survey Report No. E1, Kenya Soil Survey, Nairobi.

[30] Muriuki, H., Omore, A., Hooton, N., Waithaka, M., Ouma, R., Staal, S.J. and Odhiambo, P. (2003) The Policy Environment in the Kenya Dairy Sub-Sector: A Review. SDP Research and Development Report No. 2, International Livestock Research Institute (ILRI), Nairobi.

[31] Gachohi, J., Skilton, R., Hansen, F., Ngumi, P. and Kitala, P. (2012) Epidemiology of East Coast Fever (Theileria parva infection) in Kenya: Past, Present and the Future. Parasites \& Vectors, 5, 194.

[32] Perry, B.D. (1994) The Role of Epidemiology and Economics in the Control of Tick-Borne Diseases of Livestock in 
Africa. Kenyan Veterinarian, 18, 7-10.

[33] SNV (2013) Policy Brief 3: Management of Livestock Drug Systems. http://api.ning.com/files/K5EyQbUmZFD9Fhlmn0LhSgdL85B-SFHzsviSl0TO23A0buGH6KDlAUqMoZBcaFP-NK7 J*s93VwXvHNXtKTv0vyJ5rLS1YUrE/PolicyBrief3ManagementofLivestockDrugSystems.pdf

[34] Okello-Onen, J., Heuer, C., Perry, B.D., Tukahirwa, E.M., Ssenyonga, G.S.Z., Heinonen, R. and Bode, E. (1998) Evidence of Endemic Stability of Cattle to East Coast Fever on a Commercial Ranch in Uganda. Preventive Veterinary Medicine, 33, 241-250.

[35] Opiyo, L.M. (2011) Pastoralists' Livelihoods in the Kidepo Valley Area of Northern Uganda. A Desk Review of the Prevailing Livelihood Strategies, Development Environment and State of Resource Management in the Kidepo Valley Area and Its Environment. http://www.au-ibar.org/component/jdownloads/finish/27/783

[36] Kasozi, K.I., Tingiira, J.B. and Vudriko, P. (2014) High Prevalence of Subclinical Mastitis and Multidrug Resistant Staphylococcus Aureus Are a Threat to Dairy Cattle Production in Kiboga District (Uganda). Open Journal of Veterinary Medicine, 4, 35-43. http://dx.doi.org/10.4236/ojvm.2014.44005

[37] APUA (2010) Antibiotics in Food Animal Production: A Forty Year Debate. Vol. 28, No. 2.

[38] SNV (2013) Policy Brief 1: Management of Ticks and East Coast Fever. http://www.snvworld.org/en/download/publications/ecf_brief_1.pdf

[39] Norval, R.A.I. (1983) Arguments against Intensive Dipping. Zimbabwe Veterinary Journal, 14, 19-25. 


\section{Supplementary Information}

\section{Study Area Map}

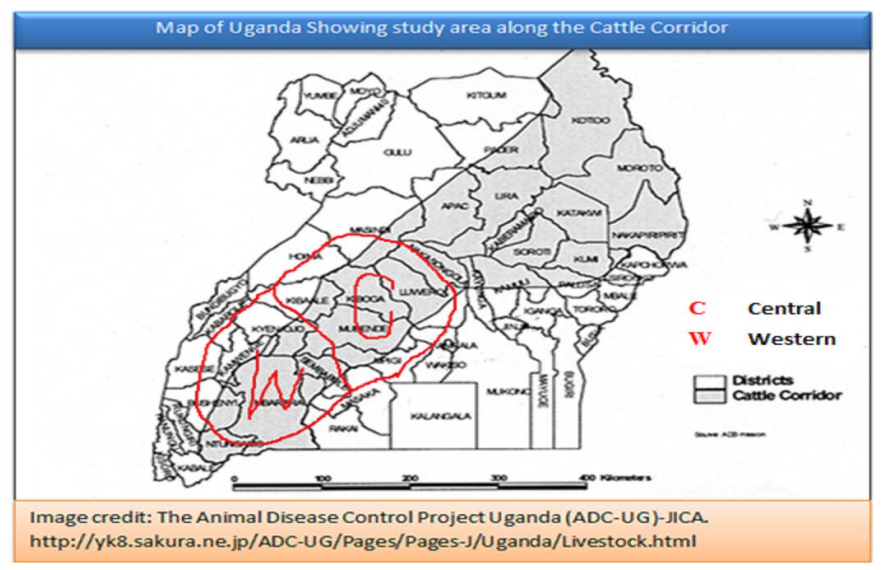

Annex 3. Map of Uganda showing the Cattle Corridor. KEY: C = Central Region; $\mathrm{W}=$ Western Region.

\section{Questionnaire}

I am a district veterinarian, currently working for the Animal Disease Control project in this region. I am currently working on a research project titled: "Epidemiology of Increasing Hemo-Parasites in Ugandan Cattle". You have been identified as a focal person in this district for the above research being a livestock farmer in cattle production. Kindly fill this questionnaire, which is meant to obtain data on disease burden, farmer treatment interventions, and common drugs that you use in this community. The findings from this research will help you to identify sources for the increasing hemo-parasitic challenge within the Central and Western regions of Uganda.

\section{Farm ID: District}

1. How do you know that your animal is sick?

2. Have you attempted any treatment, if so, what drug have you been using?

3. Where do you buy the drugs?

4. Have you consulted any professional and if any, did they visit to check on the farm of recent? If not, why?

5. What is the major challenge that you have faced in the management of this condition?

6. In your opinion, what do you think has further complicated the effectiveness of animal disease control and diagnosis delivery of recent within your community?

\section{Drug Survey}

This survey was carried out to identify the major drugs currently being used by farmers in the management of hemo-parasites on the farms visited.

Generally all farmers had identical challenges using penstrep ${ }^{\circledR}$ concurrently with OTC $^{\circledR}$, with a limited few using $\mathrm{OTC}^{\circledR}$ alone, only during the initial stages of the infection.

Few farmers relied on the use of anti-protozoal agents probably due to the high cost attached to them, despite of the fact that they are easily accessible from the drug shops in the communities.

\begin{tabular}{|c|c|c|}
\hline Sn. & Antibiotics & Anti-protozoals agents \\
\hline 1 & Penstreptomycin (Penstrep ${ }^{\circledR}$ ) & Buparvaquone (Butalex $^{\circledR}$, Butakel ${ }^{\circledR}$ ) \\
\hline 2 & Oxytetracycline $\left(\mathrm{OTC}^{\circledR}\right)$ & Parvaquone (Parvexone ${ }^{\circledR}$ ) \\
\hline 3 & & Imizol $^{\circledR}$ \\
\hline 4 & & Diminazeneaceturate (Veridium ${ }^{\circledR}$ ) \\
\hline 5 & & Isometamidiumchloride (Samorin ${ }^{\circledR}$ ) \\
\hline
\end{tabular}


Scientific Research Publishing (SCIRP) is one of the largest Open Access journal publishers. It is currently publishing more than 200 open access, online, peer-reviewed journals covering a wide range of academic disciplines. SCIRP serves the worldwide academic communities and contributes to the progress and application of science with its publication.

Other selected journals from SCIRP are listed as below. Submit your manuscript to us via either submit@scirp.org or Online Submission Portal.
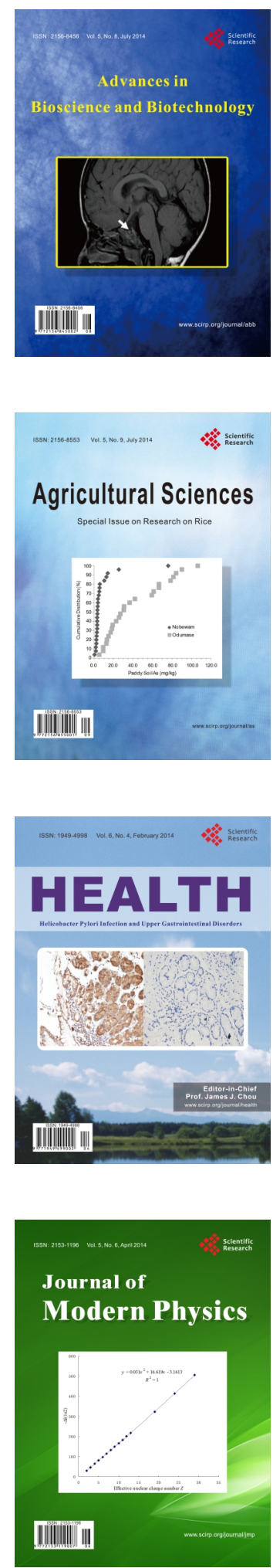
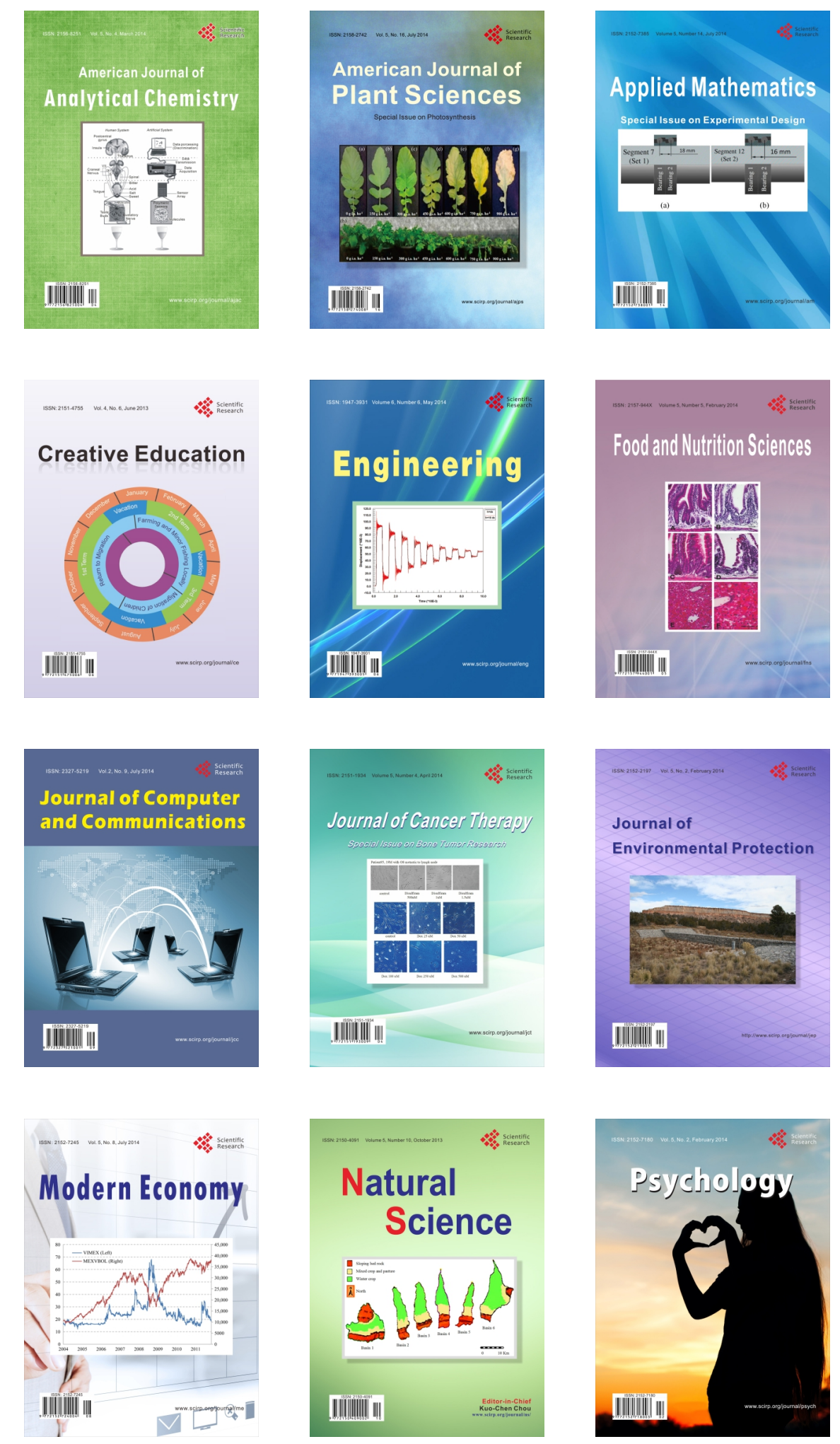